\title{
La ética del cuidado y Carol Gilligan: una crítica a la teoría del desarrollo moral de Kohlberg para la definición de un nivel moral postconvencional contextualista*
}

\author{
The Ethics of Care and Carol Gilligan: a Critique of Kohlberg's \\ Theory of Moral Development for the Definition of a \\ Postconventional Contextualist Moral Level
}

MARIA MEDINA-VICENT

\begin{abstract}
Resumen: El presente artículo pretende realizar un acercamiento a los estudios sobre el razonamiento moral humano desarrollados por Lawrence Kohlberg así como a la crítica realizada por parte de Carol Gilligan a dicho trabajo. Abordaremos pues, la teoría del desarrollo moral de Kohlberg, adentrándonos en los niveles morales preconvencional, convencional y postconvencional, con el objetivo de discernir si esta explicación evolutiva de la moralidad humana adquiere un carácter universal, o si por el contrario, se refiere a las estructuras morales de un grupo humano concreto. Más tarde, nos introduciremos en la crítica de Gilligan hacia dichos niveles morales, haciendo hincapié en la necesidad de incorporar las particularidades
\end{abstract}

\begin{abstract}
This paper aims to approach to the studies of moral human reasoning developed by Lawrence Kohlberg and Carol Gilligan's review about them. We will approach Kohlberg's Theory of Moral Development, delving in the concepts of Pre-conventional, Conventional and Post-conventional Moral Levels, in order to discern if this evolutionary explanation of human morality acquires a universal nature, or conversely, it just concerns to moral structures of a particular human group. Straightaway, we will introduce Gilligan's criticism to these moral standards, emphasizing the needed incorporation of contextual particularities in the notion of moral reasoning in order to define a
\end{abstract}

Fecha de recepción: 30/05/2014. Fecha de aceptación de la versión definitiva: 09/02/2016.

* Esta investigación se inscribe en el proyecto de investigación I+D+I "Política, empresa y educación desde la neuroética aplicada" financiado por el Ministerio de Economía y Competitividad del Gobierno de España (referencia: FI2013-47136-C2-2-P).

** Maria Medina-Vicent es Personal Investigador en Formación FPI-UJI (PREDOC/2013/16 - n ${ }^{\circ}$ ORCID: http://orcid.org/0000-0002-2716-6786) en el Departamento de Filosofía y Sociología de la Universitat Jaume I (Castelló de la Plana). Participa en el grupo de investigación "Filosofía política y ética empresarial" de la misma universidad. Sus líneas centrales de investigación son la filosofía feminista, los Critical Management Studies y la ética empresarial dialógica. Algunas de sus publicaciones más destacadas son "Women's Leadership: an Essentialist Concept?" (Journal of Feminist, Gender and Women Studies, n' 2, 2015, pp. 69-72) y "Educación moral en la ética de la razón cordial para la emergencia de nuevas masculinidades. Los Men's Studies en la agenda política feminista" (OXÍMORA. Revista Internacional de Ética y Política, $\mathrm{n}^{\circ} 7$, pp. 224-239). Contacto: medinam@uji.es 
contextuales en la noción de razonamiento moral para definir un nivel postconvencional contextualista, que nos permita confrontar las nociones de ética de la justicia y ética del cuidado.

Palabras clave: formalismo moral, ética de la justicia, ética del cuidado, nivel moral postconvencional contextualista.
Postconventional Contextualist Moral Level that would allow us to confront the notions of Ethics of Justice and Ethics of Care.

Keywords: Moral Formalism, Ethics of Justice, Ethics of Care, Contextualist Postconvecional Moral Level.

\section{Introducción}

En este artículo abordamos el debate feminista suscitado en torno a la obra de Kohlberg 1 , ya que dicho debate conforma uno de los ejes centrales de la crítica feminista contemporánea a la teoría moral universalista. La noción de una naturaleza humana universal así como de un modelo de individuo que responde a principios generalizables, forma parte del pensamiento político y filosófico propio de la teoría política moderna. Desde Aristóteles hasta Kant y el imperativo categórico ${ }^{2}$, el discurso ético clásico se ha caracterizado por fuertes pretensiones de universalidad. Autores como Habermas y Rawls ${ }^{3}$ han proseguido en los intentos de definir una ética de la justicia y el deber de corte universal que homogeniza las diferencias entre ciudadanos/as (raza, riqueza, género, etc.) en pro de un supuesto modelo de ciudadano neutral. Así, "en su aspecto negativo, esta homogeneidad al considerar las diferencias, obra en favor de la ocultación de las mismas, pues supone que no existe relación entre diferencia y desigualdad, cuando de hecho así es"4. En consecuencia, se tiende a ocultar las desigualdades sociales que se dan entre los géneros, así como entre diversos grupos sociales. Frente a esta moral de pensamiento político se han levantado diversas autoras feministas, que ponen en entredicho la noción de universalidad, promotora de un modelo masculino que es aplicado a la vida política y perpetúa las desigualdades, ignorando las particularidades de género, entre otras muchas.

A lo largo de este escrito se intentará subrayar la obra de Gilligan ${ }^{5}$ y su cuestionamiento sobre los estudios realizados por Kohlberg. Además, al final de este trabajo, se destacará la propuesta aportada por Seyla Benhabib, en referencia a la posibilidad de una complementación entre la ética de la justicia y la ética del cuidado. Así, la reivindicación de Gilligan para la incorporación de la experiencia femenina en la teoría moral, la llevará a proponer una ética del cuidado que ponga el énfasis en las cuestiones de afecto y cuidado entre los seres humanos. En compenetración con la ética de la justicia heredera de las teorías clásicas, la ética del cuidado servirá para no excluir a ninguna persona del proceso de desarrollo moral.

En definitiva, el interés que nos mueve al estudio de dicha problemática reside en la capacidad que tuvo Gilligan de destacar dentro del mundo de la teoría moral el hecho de que

1 Kohlberg, L., The Philosophy of Moral Development, San Francisco, Harper \& Row, 1981.

2 Kant, I., Fundamentación de la metafísica de las costumbres, Madrid, Editorial Espasa-Calpe, 1967.

3 Rawls, J., A theory of justice (Revised edition), Cambridge, Harvard University Press, 1999.

4 Teimil, I., «Críticas feministas a la democracia liberal», Eikasía Revista de Filosofía, n 39, julio 2011, pp. $13-37$, p. 25.

5 Gilligan, C., In a Different Voice: Psychological Theory and Women's Development, Cambridge, Harvard University Press, 1982. 
cuando la visión y experiencia de las mujeres se incorpora en cualquier ámbito, los significados que parecían inmutables, se tornan difusos ${ }^{6}$. Ésta es una idea que permite cuestionar las estructuras de nuestra sociedad para definir caminos que nos faciliten la construcción de conceptos realmente justos y más igualitarios.

\section{Aproximación a la teoría del desarrollo moral de Kohlberg}

En el periodo comprendido entre la década de los cincuenta y setenta, Kohlberg desarrolla sus estudios sobre el razonamiento moral a través de la formulación de una serie de dilemas, presentados posteriormente a un grupo de niños varones. A través de la metodología correspondiente a la entrevista semiestructurada o más concretamente denominada como Moral Judgement Interview, dicho autor se reunía con cada uno de los participantes, a quienes exponía los dilemas entendidos como "relatos de situaciones, generalmente hipotéticas, que presentan un conflicto de valores y la necesidad de tomar una decisión ante él"7. El principal objetivo de la investigación recaía en desentrañar las bases de la moralidad humana, definiendo las estructuras mentales de razonamiento lógico y moral compartidas por los seres humanos.

Kohlberg toma como punto de partida la idea piagetiana ${ }^{8}$ en su noción más general de la teoría del desarrollo cognitivo. Dicha teoría sostiene que el desarrollo de la inteligencia humana se da en cuatro etapas sucesivas que todos/as los/as niños/as pasan en el mismo orden. Por lo que cuando se entra en una nueva etapa de razonamiento, la persona ya no retrocederá a etapas anteriores. Así, etapa tras etapa, el razonamiento tiende a ser más abstracto, ya que se aprende a manejar esquemas más complejos, que permiten construir y reorganizar el conocimiento acumulado. Desde una perspectiva estructuralista se establecen una serie de estadios que van construyendo las estructuras de conocimiento, valoración y acción necesarias para constituirnos como seres morales. Al centrarse en las estructuras y no en el contenido de los juicios morales, las mismas se considerarían comunes a todas las personas, independientemente de su etnia, nacionalidad, sexo, etc.

En esta línea, avanzamos uno de los problemas ${ }^{9}$ más discutidos en la obra de Kohlberg: su pretensión de universalidad, que deja de lado las diferencias sociales, culturales, de género, etc. que se dan entre las personas. Dicha cuestión será abordada más adelante. Partiendo de esta idea, Kohlberg define una serie de dilemas que presenta a grupos de personas a lo largo de veinte años, inicialmente a niños varones en diferentes etapas de su crecimiento: infancia, adolescencia y edad adulta. Dichos dilemas hipotéticos suelen contar con un personaje protagonista que se encuentra en la disyuntiva de tomar una decisión difícil y ha de escoger entre dos valores conflictivos e igualmente valiosos, como por ejemplo, el respeto a la vida o el acatamiento de la ley. Para obtener una idea más clara

6 Benhabib, S., «Una revisión del debate sobre las mujeres y la teoría moral», Isegoría (Madrid), nº 6, 1992, pp. 37-63.

7 Linde, A., «La educación moral según Lawrence Kohlberg: una utopía realizable», Praxis Filosófica (Cali, Colombia), no 28, Enero-Junio 2009, pp. 7-22.

8 Piaget, J., El criterio moral en el niño, Barcelona, Fontanella, 1974 [Original 1932].

9 Alonso, R. y J. Fombuena «La ética de la justicia y la ética de los cuidados», Portularia (Huelva), vol. $6 \mathrm{n}^{\circ} 1$, 2006, pp. 95-107. 
de los dilemas morales, se dispone a continuación uno de los más conocidos y extendidos, el denominado "Dilema de Heinz":

En Europa una mujer estaba a punto de morir de un extraño cáncer. Había una medicina que los médicos creyeron que podría salvarla, una forma de radio que un farmacéutico de la misma ciudad había descubierto recientemente. El farmacéutico cobraba 2.000 dólares, diez veces más de lo que le había costado prepararla. El marido de la enferma, Heinz, acudió a todo el que conocía para pedir dinero prestado, pero sólo pudo conseguir la mitad de lo que la medicina costaba. Dijo al farmacéutico que su esposa estaba muriendo y le rogó que se la vendiera más barata o que se la dejara pagar más tarde. Pero el farmacéutico dijo que no. Así que Heinz desesperado robó la medicina de la farmacia para dársela a su mujer. ¿Tenía el marido que haber hecho eso? ¿Por qué? ${ }^{10}$.

Con este ejemplo se puede comprobar cómo lo interesante de los dilemas no se encuentra tanto en la respuesta final a la que llegue cada sujeto, sino en las razones que le conducen a la decisión. Y es que la clave de la teoría del desarrollo moral no recae en la sustancia de las normas morales, sino en la definición de estructuras mentales de razonamiento que serían comunes a todos los seres humanos. Sin embargo, contra los dilemas se dirá que "no reflejan problemas morales de interés universal"11, sino que son un espejo de las condiciones de una cultura etnocéntrica desarrollada en el contexto norteamericano de los años cincuenta a setenta en que dicho autor realizó sus estudios. Por esta razón, con el paso del tiempo pierden su carácter conflictivo, ya que la evolución de las sociedades provoca que los dilemas dejen de impactar en los sujetos.

A partir del análisis de los razonamientos morales de los grupos de estudio, Kohlberg afirma que el desarrollo moral de los seres humanos avanza en paralelo al cognitivo. Bajo esta concepción, el mismo estaría dividido en estadios que se alcanzan a medida que madura la persona. En esta línea, los cuatro estadios de crecimiento piagetianos de los cuales parte Kohlberg (periodo sensoriomotor, periodo preoperacional, periodo operacional concreto y periodo de las operaciones formales) ${ }^{12}$, resultan insuficientes, lo que provoca la definición de dos estadios más. Los mismos se refieren a "estructuras cognitivas que determinan las maneras de reunir y procesar información por parte del sujeto"13, y van ligados a formas concretas de asumir un papel frente al dilema (Role-taking). A continuación, abordaremos brevemente las características de los estadios ${ }^{14}$.

El primer estadio recibe el nombre de "moralidad heterónoma" y se encuentra orientado al castigo y la obediencia, con lo que el acatamiento de las normas viene condicionado por el miedo al castigo y la evitación del daño físico. En segundo lugar, nos referimos

10 Kohlberg, L., Psicología del desarrollo moral, Bilbao, Desclée de Brouwer, 1992, p. 198.

11 Linde, A., «Síntesis y valoración de la teoría sobre el desarrollo moral de Lawrence Kohlberg», Ágora Papeles de Filosofía (Universidad de Santiago de Compostela), vol. 29 n² 2, 2010, pp. 31-54, p. 43.

12 Piaget, J., El criterio moral en el niño, op. cit.

13 Linde, A., «La educación moral según Lawrence Kohlberg: una utopía realizable», op. cit., p. 11.

14 Kohlberg, L., «El niño como filósofo moral», en: Delval, J., (comp.): Lecturas de psicología del niño, Madrid, Alianza Editorial, 1978, pp. 303-314. 
al "individualismo, los fines instrumentales y el intercambio" (orientación instrumental y relativista), que nos remite a un reconocimiento de los propios intereses puestos en igualdad con los de los otros seres humanos, pero cada ser actúa en base al cumplimiento de sus propios intereses. Por lo que se refiere al estadio número tres, el de las "expectativas interpersonales mutuas y conformidad interpersonal" (orientación del niño bueno), se basa en el principio de actuar conforme deseamos que nos traten, no se tiene en cuenta al conjunto de los seres humanos, sino a esas personas que forman parte de nuestros círculos más cercanos. En cuanto al estadio cuarto, el de "sistema social y conciencia" (orientación de la ley y orden), vemos que se orienta al cumplimiento de las leyes establecidas siempre y cuando éstas no entren en conflicto con otras reglas sociales. En quinto lugar, encontramos el estadio de "contrato social o utilidad y derechos individuales" (orientación legalística), donde se toma conciencia de que cada persona tiene unos intereses relativos (referidos a un grupo concreto) y otros no relativos, estos últimos serían los que se deben mantener en todas las sociedades, ya que los relativos varían de situación en situación. El último estadio nos remite a una perspectiva de gran interés para el debate que aquí se desea tratar, ya que se centra en la noción y orientación de principios éticos universales. Las personas guían sus decisiones morales en base a principios éticos escogidos de forma autónoma, dichos sujetos respetan las leyes sociales en la medida en que no interfieran con sus valores.

Dichos estadios se enmarcan en tres niveles de desarrollo moral: nivel preconvencional, convencional y postconvencional ${ }^{15}$, que "representan perspectivas distintas que la persona puede adoptar en relación a las normas morales de la sociedad"16. A continuación se tratarán los tres niveles mencionados con mayor profundidad, viendo pues, lo que tienen en común con los seis estadios morales anteriores.

El nivel preconvencional se refiere a que la persona aborda el problema moral desde sus propios intereses, sin tener en cuenta las normas o expectativas morales de la sociedad en la que se encuentra inscrita. Es decir, el sujeto tiene en cuenta sólo sus propias necesidades y cuáles serán las consecuencias que la decisión o acción tengan para él/ella mismo/a, se podría decir que se rige por la búsqueda del placer o la evitación del dolor. Se trata de un nivel moral propio de la infancia, pero también se puede encontrar durante la adolescencia y aún en la edad adulta, aunque estos casos serían considerados por Kohlberg como aislados.

En el nivel convencional el individuo toma conciencia de su papel dentro de la sociedad y de sus grupos de afiliación, siente que forma parte de algo más grande y sabe que el conjunto espera algo de él/ella como individuo social. Por tanto, a la hora de tomar sus decisiones o hacer frente a dilemas morales, este sujeto tendrá en cuenta los valores, intereses y demandas que se le lanzan desde el entorno, ya que desea participar en el mantenimiento de los grupos y la perpetuación de lo colectivo. Cabe destacar que Kohlberg sitúa el comienzo de este tipo de razonamiento moral en la etapa adolescente y su predominio durante la edad adulta. La mayor parte de personas acceden a este nivel y generalmente no evolucionan al siguiente, ya que el paso hacia el mismo requiere un desarrollo moral podría considerarse, de corte superior.

15 Kohlberg, L., Psicología del desarrollo moral,op. cit., pp. 187-195.

16 Barra, E., «El desarrollo moral: una introducción a la teoría de Kohlberg», Revista Latinoamericana de Psicología (Colombia), vol. 19 nº 1, 1987, pp. 7-18, p. 10. 
En último lugar, el nivel postconvencional ${ }^{17}$ nos retrotrae a una especie de punto moral superior en el que la persona construye y prioriza sus propios valores sobre los de la sociedad, pero no de forma egoísta sino todo lo contrario. En otras palabras, el individuo ha adquirido el nivel de desarrollo moral más alto, aquel que le permite diferenciar sus propios valores y principios morales de aquellos que le son exigidos desde la sociedad. Por tanto, respetará todas aquellas normas y leyes que, según sus valores y principios morales propios, estén basadas en principios morales humanos universales tales como el respeto a la vida del prójimo. Éste sería el último estadio del progreso moral que es alcanzado sólo por una minoría de los adultos, y que implica tener en cuenta otros puntos de vista para llegar a acuerdos y normas universalmente aceptables por todos los afectados.

Una vez tratados tanto los estadios como los niveles de desarrollo moral, debemos abordar la cuestión de qué componentes impulsan dicha evolución, y ésta se refiere a la acción de "asumir un papel" (Role-taking) que nos permite comprender la posición del otro sujeto, entendido como otro generalizado y no concreto $^{18}$. Dicha noción del otro generalizado nos remite inevitablemente a la "posición original" rawlsiana ${ }^{19}$, donde "los sujetos son racionales, auto-interesados y conocen los hechos generales, pero no los particulares puesto que están sumidos bajo un «velo de ignorancia»" 20 . Se trata pues, de una posición desnaturalizada y supuestamente objetiva que apela a un individuo universal de corte deontológico, frente a una noción del otro particular propia de la teoría feminista y referida a las particularidades humanas. Sin embargo, a pesar de no tratarse de un yo concreto, al igual que en la teoría habermasiana, Kohlberg concede vital importancia al reconocimiento que hacemos de nosotros/as mismos/as a través de la mirada del otro ${ }^{21}$; remitiéndonos al entorno como elemento central a la hora de desarrollar nuestra moralidad, y es que "el desequilibrio o el conflicto en la interacción entre organismo y ambiente es el motor o condición para reorganizaciones estructurales hacia estadios superiores" 22 .

Para terminar, si nos paramos a analizar el hecho de que las personas que participaron en los estudios de Kohlberg eran hombres, blancos y norteamericanos, nos podemos preguntar: ¿varían las estructuras de razonamiento moral según género, etnia, nación...? Los discípulos de este autor e incluso el mismo Kohlberg plantean cuestiones similares, realizando estudios en diversas partes del mundo con el objeto de constatar la universalidad de las estructuras definidas $^{23}$. Sin embargo, en dichas investigaciones no se encuentran bases suficientes que les hagan abandonar el universalismo propio de sus teorías. Frente a estas posiciones teóricas e incluso ideológicas, Gilligan es la encargada de realizar una crítica feminista de la teoría del desarrollo moral de Kohlberg. Su trabajo resulta clave para la filosofía feminista contemporánea ya que ha marcado un punto de inflexión en la forma de abordar la mora-

17 Ramos, S. «La ética del cuidado: valoración crítica y reformulación», Laguna Revista de Filosofía (La Laguna),

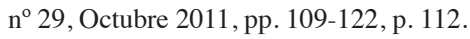

18 Benhabib, S. y D. Cornell, Teoría feminista y teoría crítica: ensayos sobre la política de género en las sociedades del capitalismo tardío, València, Edicions Alfons el Magnànim, 1990, pp. 18-20.

19 Rawls, J., A theory of justice. op. cit., pp. 102-168.

20 Lis, C., «Justicia: entre la ética del deber y la ética del cuidado», Diálogos de Derecho y Política (Universidad de Antioquía), nº 6, Enero - Abril 2011, p. 5.

21 Habermas, J. La inclusión del otro: estudios de teoría política, Barcelona, Paidós, 1999.

22 Barra, E., «El desarrollo moral: una introducción a la teoría de Kohlberg», op. cit., p. 15.

23 Kohlberg, L., Moral stages: a current formulation and a response to critics, Basel, Karger Publishers, 1983. 
lidad por parte de muchos/as autores/as, y es que para Gilligan "las mujeres no son menos maduras moralmente que los hombres, simplemente tienen una voz diferente" 24 , y dicha voz debe ser escuchada.

\section{La crítica de Gilligan hacia la teoría del desarrollo moral de Kohlberg: definición de un nivel moral postconvencional contextualista}

La importancia de las ideas de Gilligan en el marco de la filosofía feminista resulta vital, ya que fue dicha autora quien marcó el inicio del debate contemporáneo sobre mujeres y teoría moral. Con la publicación de su obra In a Different Voice (1982)25, mostró las consecuencias sociales de plantear la cuestión de las mujeres dentro de los parámetros del discurso científico establecido ${ }^{26}$, y señaló que tanto los teóricos morales como los de la psicología habían "adoptado implícitamente la vida del varón como norma, tratando de crear mujeres a base de un patrón masculino" 27 . De este modo, puso de relieve la necesaria incorporación de la experiencia femenina en la teoría moral y política, históricamente asociada a los hombres y al ámbito público. La crítica de Gilligan hacia la obra de Kohlberg se centra en señalar que dicha teoría es válida sólo para medir un aspecto de la orientación moral focalizado en la justicia y los derechos, dejando de lado las cuestiones particulares o de vida buena ${ }^{28}$. Sin embargo, al contrario de afirmar la existencia de una moralidad propia de las mujeres, su crítica muestra que otros caminos de desarrollo moral son posibles. Por tanto, Gilligan trata de expandir el ámbito de la moralidad proponiendo la noción de ética del cuidado y sentando las bases para su posterior diálogo y complementación con la ética de la justicia.

A la hora de poner en práctica el test de Kohlberg en sus propias investigaciones, dicha autora observó que las mujeres obtenían de forma general puntuaciones bajas y no solían llegar al nivel moral final que había categorizado el mismo autor, y que se supone, es de corte superior. En un primer momento, dicha evidencia fue interpretada por Kohlberg como una incapacidad de la mujer para emitir juicios morales superiores, provocada por su emplazamiento en la sociedad, referido al espacio privado-doméstico ${ }^{29}$, donde se desarrollan los temas del cuidado, afecto y responsabilidad. Así pues, volviendo a la teoría del desarrollo cognitivo de Piaget, se podría entender que las mujeres se hallaban en una especie de inmadurez moral fruto de su experiencia en el ámbito privado. En un principio, dichas premisas podrían resultar aceptables para un mundo basado en la dominación masculina, por esta razón, tuvo que ser una mujer la que señalara el problema de desigualdad que implicaba realizar dicha afirmación.

En lugar de pasar por alto esta evidencia, Gilligan se adentró en la problemática a partir de dos premisas básicas de la teorización feminista: la realidad social se organiza en base

24 Gilligan, C., In a Different Voice: Psychological Theory and Women's Development, op. cit., pp. 7-9.

25 Íbid.

26 Benhabib, S., El ser y el otro en la ética contemporánea: feminismo, comunitarismo y posmodernismo, Barcelona, Gedisa, 2006, p. 203.

27 Gilligan, C., La moral y la teoría. Psicología del desarrollo femenino, México, Fondo de Cultura Económica, 1985 , p. 21.

28 Benhabib, S., «Una revisión del debate sobre las mujeres y la teoría moral», op. cit.

29 Murillo, S., «Los peligros de asimilar privado a doméstico», Fisuras de la cultura contemporánea (Madrid), $\mathrm{n}^{\circ}$ 6, 1998, pp. 158-163. 
a un sistema sexo-género ${ }^{30}$ que define nuestra forma de percibir el mundo; y dicho sistema se basa en la dominación patriarcal ${ }^{31}$, en el que un grupo humano (los hombres) detenta el poder sobre otro (las mujeres). Preguntándose el por qué de este hecho, y no dando por sentado que se debía a una supuesta "inmadurez moral" de las mujeres, Gilligan mostró que en los estudios de Kohlberg no se tenían en cuenta las estructuras sociales de exclusión sexo-género, ni el hecho de que las experiencias concretas de los sujetos condicionan los modos que tienen de desarrollar sus razonamientos morales.

Desde la posición de Gilligan, como aclarará en el prólogo del año 1993 a su obra In a different voice donde responde a las críticas y malentendidos de su trabajo, la posición que una persona ocupa en el mundo determina su modo de desarrollar la moral: "For example, it seems obvious to me, as a psychologist, that differences in the body, in family relationships, and in societal and cultural position would make a difference psychologically" 32 . En esta línea, Gilligan pone en entredicho la justicia universalista contemporánea basada en un modelo de ciudadanía construido a través de lo común y dejando de lado las diferencias ${ }^{33}$, priorizando pues una moralidad sobre otra y a un grupo humano sobre el otro: hombres por encima de mujeres, esfera pública sobre esfera privada, justicia y deber sobre cuidado y responsabilidad. Gilligan se afanó en mostrar que no existe un modo único de entender la moralidad, sino que "los caminos divergentes de desarrollo moral que siguen chicos y chicas en términos de diferencias de experiencia (realidad vivida)" 34 , marcan diferentes modos de desarrollar la moral. Así, en referencia a una de sus entrevistadas, Gilligan señala que:

Aunque parece clara la naturaleza postconvencional de la perspectiva de Diane, su juicio de los dilemas morales no satisface las normas del pensamiento con principios en la orientación de la justicia. Sin embargo, este juicio refleja una concepción moral diferente, en que el juicio moral va orientado hacia cuestiones de responsabilidad y cuidado $^{35}$.

De esta afirmación se desprende que no todas las personas en el nivel postconvencional de desarrollo moral, tienen porqué centrar su perspectiva en las cuestiones de justicia universal, sino que pueden centrarse en las de cuidado. Así, lejos de la teoría del desarrollo moral de Kohlberg centrada en el monismo moral, en que se afirma que solamente existe

30 El sistema sexo-género se refiere a las relaciones sociales entre mujeres y hombres dentro de un sistema de poder que define condiciones sociales distintas para ambos grupos en función de sus papeles sociales asignados y de su posición de poder o desposesión sobre los principales recursos. Gayle Rubin lo define como "el sistema de relaciones sociales que transforma la sexualidad biológica en productos de actividad humana y en el que se encuentran las resultantes necesidades sexuales históricamente específicas" (Rubin, G., «The traffic in women: notes on the political economy of sex» en: R. Reiter (ed.): Toward an Anthropology of Women, New York, Monthly Review Press, 1975, pp. 157-210).

31 Pateman, C., El contrato sexual, Madrid, Anthropos, 1995.

32 Gilligan, C., «Letter to readers, 1993», en: C. Gilligan: In a Different Voice: Psychological Theory and Women's Development, Cambridge, Harvard University Press, 1993, p. XI.

33 Guerra, M. J., « ¿Subvertir o situar la identidad? Sopesando las estrategias feministas de Judith Butler y Seyla Benhabib», Daímon (Murcia), n 14, 1997, pp. 143-154, p. 153.

34 Scott, J.W., «El género: una categoría útil para el análisis histórico» en: M. Lamas (comp.): El género: la construcción cultural de la diferencia sexual, México, PUEG, 1996, pp. 265-302.

35 Gilligan, C., La moral y la teoría. Psicología del desarrollo femenino, op . cit., p. 165. 
una maduración moral correcta; el trabajo de Gilligan se enmarca dentro del pluralismo moral, según el cual "puede existir más de una forma de moralidad y de madurez moral correcta" 36 . En esta línea, Murphy y Gilligan ${ }^{37}$ realizarán una distinción entre el "formalismo postconvencional" y el "contextualismo postconvencional", donde ya no se trataría tanto de definir estructuras morales universales, sino de explicar el desarrollo moral desde una perspectiva que incluya las relaciones de cuidado. Dicha distinción sirve de base a Gilligan para defender una ética del cuidado postconvencional. En consecuencia, en el contextualismo postconvencional,

(...) la persona define sus reglas de acuerdo con principios universales de justicia, pero evaluando la acción en función de los derechos y valores de cada sujeto, i.e., se apoya en las experiencias de cada persona. Sin embargo, en el nivel del formalismo postconvencional, la persona argumenta su respuesta ante el dilema moral justificándola ante principios éticouniversales, como el derecho de cada uno a la igual consideración de sus demandas en cualquier situación, fundamento de la sociedad democrática ${ }^{38}$.

Para Kohlberg, el formalismo postconvencional era el estadio superior de razonamiento moral, un estadio al que pocas mujeres llegaban, ya que ellas ofrecían otra línea de razonamiento que incluía las relaciones y experiencias concretas de los involucrados. Así, Kohlberg arguyó que si las mujeres tuviesen una experiencia en la esfera pública, seguirían el mismo esquema de razonamiento que los hombres, una estructura de justicia universal, fortaleciendo así la idea de que las mujeres aún tenían una madurez moral que alcanzar. Se priorizó la justicia encarnada en el modelo de individuo moderno universal neutro. Sin embargo, no todos/as pueden encajar en dicho modelo, ya que el principio de universalidad deja de lado las diferencias de género, raza y otra índole, lo que implica una discriminación sexual que permite que el prototipo ideal de individuo libre entendido como hombre con unos recursos y una posición social determinada, se imponga y subordine a cualquier otro grupo ${ }^{39}$.

En esta línea, "la hipótesis de la universalidad del desarrollo moral, tal como fue descrita por Kohlberg, es discutible" 40 , ya que existe otro modo de entender la moralidad, otro proceso que puede llevarnos a establecer juicios morales verdaderamente justos. Y es que "la idea de que un mundo en el que las familias u organizaciones hogareñas de tipo familiar muestran su apoyo, preocupaciones y cariño entre sí es preferible a un mundo en el que éste

36 Cruz, M., «Debates dentro de la psicología del desarrollo moral», Revista de Psicología Universidad de Antioquía, Vol. 6, nº 1, 2014, pp. 113-124, p. 114.

37 Murphy, J.M. y Gilligan, C., «Moral Development in Late Adolescence and Adulthood: A Critique and Reconstruction of Kohlberg's Theory», Human Development (Cambridge), vol. 23 n 2, 1980, pp. 77-104.

38 Martínez, I. y Bonilla, A., Sistema sexo/género, identidades y construcción de la subjetividad, València, Publicacions de la Universitat de València, 2000, p. 103.

39 Fraser, N., «¿Qué tiene de crítica la teoría crítica? Habermas y la cuestión del género», en: Benhabib, S. y Cornell, D. (eds.): Teoría feminista y teoría crítica, ensayos sobre la política de género en las sociedades del capitalismo tardío, València, Edicions Alfons el Magnànim, València, 1990, pp. 49-88.

40 Linde, A., «Síntesis y valoración de la teoría sobre el desarrollo moral de Lawrence Kohlberg», op. cit., p. 42. 
no es el caso, y esto último es una afirmación moral universalizable" ${ }^{41}$. Así pues, se destaca que las acciones que desarrollan los individuos en el mundo de la vida (en términos habermasianos), suponen también los pilares para la definición de principios morales basados en el respeto, el amor y la reciprocidad. Y que los apuntes referidos a la forma en que las mujeres definen su perspectiva moral a partir de sus vivencias en el ámbito del cuidado, es una señal de madurez en el juicio que permite entender el mundo no como un ente aislado, sino como un ser situado dentro de una red de conexiones ${ }^{42}$.

\section{4. Ética de la justicia y ética del cuidado: un encuentro necesario}

A partir del nacimiento del Estado Moderno, el espacio social es disociado en dos esferas, lo público y lo privado, que se encuentran en una interrelación constante y marcan la posición de cada género en la sociedad. La distribución de los géneros en las diferentes esferas sociales condiciona las vivencias y la forma que tienen de percibir el mundo mujeres y hombres, ya que las primeras son "adscritas" al ámbito privado entendido como doméstico, mientras que los segundos se destinan al espacio público, desarrollando cargos de relevancia social en la política, economía, tecnología, etc. ${ }^{43}$ La noción de ética de la justicia sobre la que se sustenta la teoría del desarrollo moral de Kohlberg nos remite directamente a dicha separación de los espacios y al universalismo normativo de corte deontológico ${ }^{44}$. Más allá de la pretendida imparcialidad que se supone debe vertebrar las normas de justicia universales, Gilligan nos permite dudar acerca de la verdadera justicia que existe tras una resolución imparcial de los dilemas morales. Y abre las puertas para pensar una moral de la responsabilidad y el cuidado enmarcada en el seno de una red de relaciones donde las particularidades, entendidas como diferentes transiciones y experiencias de vida, son necesarias para llegar a juicios morales justos ${ }^{45}$. Por tanto, la crítica de Gilligan nos permite desvelar las insuficiencias de la ética de la justicia, con la intención de repensar una ética del cuidado que tenga en cuenta las experiencias de las mujeres, eso sí, abriendo la posibilidad de establecer un diálogo entre justicia y cuidado que permita integrar ambas éticas.

Como se puede observar, las anteriores afirmaciones en torno a los espacios asignados y el modelo de individuo universal, nos remiten directamente al debate generado en torno a la idea de que hay dos orientaciones morales: la ética de la justicia y la ética del cuidado. Al considerar la justicia como el eje central de la moralidad, habíamos visto que se dejaban de lado otros componentes que pueden resultar igual de valiosos para generar juicios morales justos, como por ejemplo las relaciones afectivas. Esto implica que se "desatiende la moralidad cotidiana, interaccional y supone que el punto de vista público

41 Benhabib, S., El ser y el otro en la ética contemporánea: feminismo, comunitarismo y posmodernismo, op. cit., p. 214.

42 Lis, C., «Justicia: entre la ética del deber y la ética del cuidado», op. cit.

43 Pateman, C., «Críticas feministas a la dicotomía público/privado», en: Castells, C.: Perspectivas feministas en teoría política, Buenos Aires, Paidós, 1996, pp. 31-53.

44 Pateman, C., El contrato sexual, op. cit.

45 Gilligan, C., La moral y la teoría. Psicología del desarrollo femenino, op . cit., p. 277. 
de la justicia es el centro de la teoría moral"46, dejando fuera las cuestiones relativas al ámbito privado, considerado tradicionalmente ámbito del cuidado. Así pues, frente a una ética de la justicia de carácter normativo centrada en los derechos, la igualdad y basada en el acuerdo o contrato social; la ética del cuidado, referida a las conexiones entre las personas y las responsabilidades que subyacen a sus relaciones, permite vislumbrar las carencias de un universalismo que borra de la ecuación cuestiones tan importantes como el cuidado. Y es que "subyacente en una ética de cuidados y atención hay una lógica psicológica de relaciones, que contrasta con la lógica formal de imparcialidad que imbuye el enfoque de la justicia" 47 . Por tanto, nos interesa conocer las bases de la ética del cuidado, para comprobar que una complementariedad con la de ética la justicia es el camino más adecuado para conseguir una sociedad realmente ética.

Cabe señalar pues, que un concepto central de la ética del cuidado es el de responsabilidad, y su punto de partida se basa en "la comprensión del mundo como una red de relaciones en la que nos sentimos inmersos y de donde surge un reconocimiento de la responsabilidad hacia los otros"48. Consecuentemente, se pretende pasar del formalismo de principios abstractos propio de la ética de la justicia y la imparcialidad del "otro generalizado", entendido como un modelo de individuo universal e imparcial; a la adopción del punto de vista del "otro concreto". Es decir, se pretende avanzar del "punto de vista desde el que se pueden enjuiciar imparcialmente cuestiones morales" 49 , a las situaciones concretas de cada ser, que entran en juego en la definición de lo moral. La puesta en valor de las nociones de justicia que se hallan en el ámbito del mundo de la vida, nos permite ver que "la definición del dominio moral, no sólo en la teoría de Kohlberg sino en las teorías contractualistas, conducen a una privatización de la experiencia de la mujer y a la exclusión de su consideración desde un punto de vista moral" 50 . Por tanto, desvela lo que de patriarcal e incluso paternalista esconden las teorías morales universalistas, que con sus principios universalizables pasan por encima de las particularidades ya no sólo de las mujeres, sino de distintos grupos minorizados, dando por válida una sola parte de la vida social: la del ámbito público. Con la operación de Gilligan se estarían consiguiendo hacer patentes las desigualdades generadas por el contrato social originario que esconde un contrato sexual que legitima la disociación de los ámbitos público y privado ${ }^{51}$.

Por otro lado, las aportaciones de Gilligan fueron contestadas por diversos autores entre los que se encuentran el mismo Kohlberg y el filósofo Habermas ${ }^{52}$. Este último señala que "el tipo de problemas que Gilligan pone de relieve pertenecen a la periferia de la teoría moral y que son anomalías o problemas subsidiarios de un paradigma científico que es, por lo demás, adecuado" 53 . Con esto quiere decir que aquellos problemas que se dan en el ámbito

46 Benhabib, S., El ser y el otro en la ética contemporánea: feminismo, comunitarismo y posmodernismo, op. cit., p. 187.

47 Gilligan, C., La moral y la teoría. Psicología del desarrollo femenino, op. cit., p. 126.

48 Alvarado, A., «La ética del cuidado», Revista Aquichan (Bogotá, Colombia), nº 4, Octubre 2004, pp. 30-39, p. 31.

49 Habermas, J., Aclaraciones a la ética del discurso, Madrid, Trotta, 2000, p. 159.

50 Benhabib, S., El ser y el otro en la ética contemporánea: feminismo, comunitarismo y posmodernismo, op. cit., p. 176.

51 Pateman, C., El contrato sexual, op. cit.

52 Habermas, J., Conciencia moral y acción comunicativa, Barcelona, Ediciones Península, 1996.

53 Benhabib, S., «Una revisión del debate sobre las mujeres y la teoría moral», op. cit. p. 43. 
privado o mundo de la vida, son temas personales que no morales, y que por tanto, no se refieren a cuestiones de justicia, sino a cuestiones de vida buena que recaen en el criterio evaluativo de cada persona. Con lo que para ambos autores, Gilligan estaría confundiendo los temas de justicia con los de vida buena, desdibujando así las fronteras de lo moral ${ }^{54}$. Desde esta posición, se entendería que la resolución de dilemas en el ámbito familiar sería fruto de lo especial de la relación existente entre dichas personas, es decir, de la relación afectiva y de cuidado que existiría entre los miembros de la familia. Desde la teoría kantiana, dicha obligación se puede entender en términos de deberes positivos de afecto o benevolencia ${ }^{55}$, que entrarían dentro de lo que Kant llama deberes imperfectos ${ }^{56}$, y que en la Metafísica de las costumbres denomina como "deberes éticos o de obligación amplia". De esta manera, los deberes de afecto o benevolencia se refieren a hacer el bien a los demás por el amor que sentimos hacia ellos, "el hacer bien por amor nace del corazón, en tanto que el hacer bien por obligación tiene su origen en principios del entendimiento. Uno puede, por ejemplo, hacer bien a su mujer por amor, mas cuando desaparece la inclinación, ello se hace por obligación" 57 . Así, el cuidado que se da de un miembro de la familia a otro sería considerado como fruto del amor, un tema que desde la perspectiva universalista escaparía del ámbito público y que por tanto, no debería interferir en los razonamientos morales.

Una vez abierto el debate, Seyla Benhabib nos ofrece una vía para el encuentro de la ética de la justicia con la ética del cuidado, ya que entiende que concebir las cuestiones personales como cuestiones morales es necesario, pero renunciar al universalismo significaría dejar de considerar a cada ser humano con igual valor. Por esta razón, hay que "someter los principios y las normas deontológicas a la prueba de la realidad" 58 , y uno de los modos es teniendo en cuenta tanto los principios universalizables como los contextos de aplicación. Por tanto, Benhabib entenderá la aportación de Gilligan como un reto para las teorías feministas y la teoría moral universalista, ya que aborda un problema vital referido al origen mismo de la teoría moral moderna y de la separación de las esferas pública y privada. Dicho problema se refiere a "cómo sostener la centralidad de la justicia y el cuidado en las vidas de las personas y cómo ampliar el ámbito de lo moral para incluir las consideraciones que se derivan de ese cuidado sin que ello implique dejar de lado las constricciones que le impone el universalismo a la moral" 59 . Para esto, Benhabib propone concebir las cuestiones de vida buena como temas morales, sin prescindir del universalismo kantiano, ya que una ética del cuidado solitaria corre el riesgo de situarnos en una posición en la que consideremos que sólo es bueno aquello que beneficia a quienes queremos, y esta posición no sería justa porque sería la moral de la satisfacción. Por tanto, la propuesta de Benhabib propone "integrar aspectos normativos de la teoría de Habermas junto con intereses feministas"60.

54 Habermas, J. Conciencia moral y acción comunicativa, op. cit., pp. 199-213.

55 Kant, I., Lecciones de ética, Barcelona, Editorial Crítica, 1988, pp. 235-237.

56 Kant, I., Fundamentación de la metafísica de las costumbres, Madrid, Editorial Espasa-Calpe, (1785) 1967, p. 73.

57 Kant, I., Lecciones de ética, op. cit., 1988, p. 235.

58 Linde, A., «Síntesis y valoración de la teoría sobre el desarrollo moral de Lawrence Kohlberg», op. cit., p. 44.

59 Benhabib, S., «Una revisión del debate sobre las mujeres y la teoría moral», op. cit. p. 50.

60 Benhabib, S. y D. Cornell, Teoría feminista y teoría crítica: ensayos sobre la política de género en las sociedades del capitalismo tardío, op. cit., p. 19. 
Para comprender la propuesta de diálogo entre ética de la justicia y ética del cuidado que realiza Benhabib, debemos partir del reconocimiento de que "la razón ha sido considerada por la tradición filosófica occidental como lo que es universal, y como lo que trasciende las idiosincrasias de las perspectivas parciales e individuales"61. En vistas a este hecho, el feminismo se ha esforzado por proponer una reconceptualización de dicha razón, que se ha centrado en la esfera pública y en aquellos que la habitan: los hombres. Así, desde el feminismo se pretenden poner de relieve,

(...) las difíciles relaciones de la modernidad ético-política con las mujeres en lo que concierne al espacio público. Un espacio público moderno configurado no sólo a la medida de la experiencia masculina del mundo, sino empeñado en que su sesgo androcéntrico no sea cuestionado al camuflarse tras un universalismo que declara que hay sitio para todos, pero que, inmediatamente, amparado en su coartada retórica, establece sin rubor las exclusiones pertinentes para seguir consiguiendo que lo público sea el coto privado de los varones ${ }^{62}$.

Por tanto, el otro generalizado producto de la Modernidad es el paradigma de la moralidad presente en las obras de los teóricos del contrato social y las teorías de Rawls. Consecuentemente, los feminismos al atacar este tipo de racionalidad reivindican la importancia de incluir las diferencias particulares dentro de la fundamentación moral de las comunidades políticas, enfrentándose al hecho de que el "yo abstracto" de Rawls no permite incluir el punto de vista del otro concreto. La operación de reformular la razón universalista en vistas de que incluya las experiencias particulares de los sujetos, la lleva a cabo Benhabib partiendo de los paradigmas habermasianos. Así, propone que hay que razonar desde la posición de los demás teniendo en cuenta necesidades concretas, talentos y capacidades específicas ${ }^{63}$, para poder incorporar el punto de vista del otro concreto en nuestras deliberaciones morales. Benhabib sostiene que dicha operación se puede llevar a cabo a partir de la ética discursiva habermasiana y los principios del discurso práctico ${ }^{64}$, "bajando el hipotético agente moral idealizado al suelo del diálogo real de los agentes morales que se comunican entre sí" 65 .

De esta manera, Benhabib toma la teoría habermasiana como punto de partida para posibilitar el reconocimiento de las diferentes identidades y necesidades de cada ser humano, sin renunciar a la consecución de principios morales universalizables. Así, sugiere que "la ética comunicativa adecuadamente formulada puede mediar entre el punto de vista de el(los) otro(s) generalizado(s) y el(los) otro(s) concreto(s), al sintetizar la justicia con la solicitud, la autonomía con la capacidad de entrar en contacto"66. Por tanto, dicha autora ve el

61 Íbid., p. 18.

62 Guerra, M.J., «Mujer, identidad y espacio público», Contrastes. Revista Interdisciplinar de Filosofía, Vol. 4, 1999, pp. 45-64, p. 46.

63 Benhabib, S., El ser y el otro en la ética contemporánea: feminismo, comunitarismo y posmodernismo, op. cit.

64 Habermas, J., Aclaraciones a la ética del discurso, Madrid, Trotta, 2000.

65 Guirao, C., «Modernidad y postmodernidad en el feminismo contemporáneo», Feminismo/s, nº 15, 2010, pp. 221-234, p. 232.

66 Benhabib, S. y D. Cornell, Teoría feminista y teoría crítica: ensayos sobre la política de género en las sociedades del capitalismo tardío, op. cit., p. 19. 
potencial de la teoría de Habermas para cambiar la exclusión social de las mujeres, porque éstas tienen las herramientas para incorporar su voz en un diálogo intersubjetivo que tenga en cuenta a todos los/as afectados/as. Propone pues, el diálogo entre el otro generalizado y el otro concreto, porque "el reconocimiento de la dignidad y valía del otro generalizado es una condición necesaria aunque no suficiente para definir el punto de vista moral en las sociedades modernas. En este sentido el otro concreto es un concepto crítico que designa los límites ideológicos del discurso universalista ${ }^{67}$.

En resumen, una de las claves en el debate sobre ética de la justicia y ética del cuidado reside en concebir el dominio moral desde la diferenciación entre la justicia y la vida buena, sin embargo, tenemos como obligación repensar esta disyuntiva. Porque si perpetuamos la idea de que la justicia se desarrolla en el ámbito público y las cuestiones de vida buena en el privado, legitimamos el modelo que se desea transformar desde el feminismo. Dicho de otro modo, debemos conjugar los puntos de vista individuales con los colectivos, para incluir en los procesos morales las perspectivas de todos/as, no desde la posición de un "otro" neutralizado, sino del otro concreto. En esta línea, Benhabib propone en lugar de un universalismo sustitucionalista, un universalismo interactivo ${ }^{68}$ que permita reorganizar estructuralmente las bases sociales del sistema de dominación patriarcal, propuesta que desde nuestro punto de vista, resulta la más adecuada para construir una sociedad justa e igualitaria.

\section{Conclusiones}

A lo largo del presente artículo se ha comprobado la vital importancia que tiene para la filosofía feminista contemporánea el debate generado en torno al universalismo de la teoría del desarrollo moral de Kohlberg. Y es que la crítica de Gilligan hacia dichos estudios, revolucionó la forma de entender la moralidad humana y abrió el camino para que otros/as autores/as desarrollasen diferentes vías de la ética del cuidado. Desde entonces, dicha ética se ha aplicado a numerosos campos, como el de la medicina y la enfermería ${ }^{69}$, los estudios de paz $^{70}$, y el ámbito de la política internacional ${ }^{71}$.

Gilligan cuestionó el trabajo de Kohlberg debido a las bajas puntuaciones que recibían las mujeres participantes en sus estudios sobre dilemas éticos. Su investigación con mujeres y sobre dilemas éticos como el aborto, llevó a la autora a encontrar una voz diferente en las mujeres, que ella misma bautizaría como ética del cuidado. En este sentido, resulta importante destacar que "esa distinta voz moral de las mujeres no responde a diferencias

67 Benhabib, S., «El otro generalizado y el otro concreto: la controversia Kohlberg-Gilligan y la teoría feminista» en: Benhabib, S. y Cornell, D. (eds.): Teoría feminista y teoría crítica, ensayos sobre la política de género en las sociedades del capitalismo tardío, València, Edicions Alfons el Magnànim, València, 1990, pp. 119-150, p. 144.

68 Benhabib, S., «Una revisión del debate sobre las mujeres y la teoría moral», op. cit.

69 Noddings, N., Caring. A Femenine Approach to Ethics and Moral Education, Berkeley, University of California Press, 1984.

Watson, J., Nursing: The Philosophy and Science of Caring, University of Colorado, Boulder, 2008.

70 Comins, I., «La ética del cuidado; contribuciones a una transformación pacífica de los conflictos», Feminismo/s, n 9 , junio 2007, pp. 93-105.

71 Robinson, F., Globalizing Care. Ethics, Feminist Theory and International Relations, Oxford, Westview Press, 1999. 
biológicas o innatas entre hombres y mujeres sino a una distinta socialización. Esta distinta voz se caracteriza por definir la moral en términos de relaciones interpersonales y no tanto de reglas o principios abstractos." $72 \mathrm{Al}$ percatarse de este hecho, la autora puso en entredicho la pretendida universalidad de un modelo de desarrollo moral que otorgaba capacidades morales menores a las mujeres y que por tanto, era una estructura que legitimaba la dominación sexual o de género.

Y es que Kohlberg consideró la justicia y los derechos por encima de las cuestiones afectivas y de cuidado, justificando las bajas puntuaciones femeninas en su inexistente papel en la esfera pública. Sin embargo, Gilligan entendió el hecho de que la mayor parte de mujeres se quedaran en etapas del desarrollo moral donde se produce un predominio de la puesta en valor del bienestar de los demás, como el producto de los condicionantes socio-psicológicos que determinan la manera de ser, estar y actuar en el mundo por parte de las mujeres. Porque, teniendo en cuenta dicha afirmación, se puede comprender que "la sensibilidad a las necesidades de los demás y el asumir responsabilidad por cuidar de ellos llevan a las mujeres a escuchar voces distintas de las suyas y a incluir en sus juicios otros puntos de vista" 73 , mostrando una preocupación mayor por las relaciones y sus responsabilidades con para los/as demás.

Como hemos visto, la dominación patriarcal basada en la disociación de los ámbitos público y privado en la esfera social, provoca la asignación de espacios diferenciados para mujeres y hombres. Mientras a las mujeres les ha sido socialmente asignada la tarea del cuidado de los/as otros/as, "las capacidades instrumentales se han quedado en el dominio masculino"74, escindiendo amor y trabajo. En este orden de cosas, Gilligan detectó que "existe una relación entre el modo de razonamiento moral y la concepción del yo de hombres y mujeres"75, lo que sustentó su aportación sobre la idea de que hombres y mujeres tienen modos diferentes de plantear los dilemas morales, así como de razonar y plantearse cuestiones de índole moral debido a su posición social en el mundo. A través de su obra, subrayó la necesidad de incorporar la visión de las mujeres en el ámbito de la teoría moral y política, abriendo un diálogo entre el universalismo y una concepción más contextual de la moral. Porque al incorporar el punto de vista del otro concreto en las deliberaciones morales y tener en cuenta las individualidades de cada cual, se van a poder considerar todos los seres racionales como individuos con una historia, una identidad y una constitución afectivo-emocional concretas ${ }^{76}$.

Por tanto, el trabajo de Gilligan nos permite ser conscientes de que la dicotomía públicoprivado condiciona nuestro papel como ciudadanos y ciudadanas, así como nuestra posición en el mundo y el modo que tenemos de percibirlo. Al mismo tiempo, va a definir nuestro modo de desarrollar los razonamientos morales, que al fin y al cabo, se refieren al modo

72 Comins, I., «Del miedo a la diversidad a la ética del cuidado: una perspectiva de género», Convergencia. Revista de Ciencias Sociales, n 33, septiembre-diciembre 2003, pp. 97-122, p. 107.

73 Gilligan, C., La moral y la teoría. Psicología del desarrollo femenino, op. cit., p. 38.

74 Íbid., p. 39.

75 Fascioli, A., «Ética del cuidado y ética de la justicia», Revista ACTIO (Facultad de Humanidades y Ciencias de la Educación de la Universidad de la República de Uruguay), nº 12, 2010, p. 44.

76 Beltrán, E., «Público y privado: sobre feministas y liberales: argumentos en un debate acerca de los límites de lo político», Doxa (Universidad de Alicante), n 15-16, 1994, pp. 389-405, p. 399. 
en que nos relacionamos con los demás. Desde nuestro punto de vista, se vuelve más que necesaria la incorporación de la experiencia de las mujeres en el seno de las teorías morales universalistas, ya que es cuestión de justicia definir una moralidad que no privatice dicha experiencia, sino que abra caminos para complementar los principios de la ética de la justicia con la ética del cuidado. Es decir, que nos permita construir una ciudadanía completa y reconocer las cuestiones de la vida buena no como cuestiones privadas, sino como parte irrenunciable del interés público y de la moralidad humana. Porque, como bien diría Gilligan, "comprender cómo la tensión entre responsabilidad y derechos sostiene la dialéctica del desarrollo humano es ver la integridad de dos modos diferentes de experiencia que, al final, están conectados" 77 .

Posteriormente, el desafío que lanzó Gilligan encendió el debate sobre si la ética del cuidado es realmente una ética feminista o femenina ${ }^{78}$. En este sentido, es importante recordar que Gilligan distingue entre ética feminista, de cuidado y responsabilidad, y ética femenina de autosacrificio, señalando que "el cuidado se caracteriza por el sentimiento de formar parte de una red de relaciones con ternura y responsabilidad, para cumplir con la cual no es necesario destruir el propio yo" "79. Con lo que la propuesta de Gilligan se identifica con un enfoque feminista de la moral, que rehúye el autosacrificio en ciernes de la libertad de las mujeres.

Queda claro pues que el trabajo de Gilligan supuso un antes y un después en el pensamiento feminista, pero también en su aplicación desde lo moral a otros ámbitos, trazando un viaje sin retorno desde las cuestiones de género a las cuestiones de poder ${ }^{80}$. Pero lo más importante fue poner de relieve que cuando se incorpora la voz de las mujeres, todo lo que se creía inamovible empieza a tambalearse. Así pues, una de las grandes aportaciones de dicha autora fue el mostrar que "el modelo de Kohlberg no puede ser aplicado universalmente de modo objetivo porque tiene las limitaciones inherentes a su origen cultural occidental e ideológicamente liberal" 81 .

77 Gilligan, C., La moral y la teoría. Psicología del desarrollo femenino, op. cit., p. 281.

78 Kohen, D., Rethinking Feminist Ethics: care trust and empathy, London, Routledge, 1998.

79 Carosio, A., «La ética feminista: más allá de la justicia», Revista Venezolana de Estudios de la Mujer, Vol. 12, $\mathrm{n}^{\mathrm{o}} 28$, junio 2007.

80 Koggel, C., y Orme, J. «Care Ethics: New Theories and applications», Ethics and Social Welfare, Vol. 4, $\mathrm{n}^{\circ} 2$, 2010, pp. 109-114, p. 109.

81 Linde, A., «Síntesis y valoración de la teoría sobre el desarrollo moral de Lawrence Kohlberg», op. cit., p. 43. 